\title{
Wind Loads on Tall Buildings: A Comparative Study of the International Wind Codes and Numerical Simulation
}

\author{
H. M. A. D. Jayasundara, S. M. N. H. Koliyabandara and K. K. Wijesundara
}

\begin{abstract}
Wind codes and standards have been used commonly when designing regularshaped tall buildings to withstand wind loads. High-Frequency Base Balance (HFBB) data analysis and Computational Fluid Dynamics (CFD) have now emerged as alternative techniques to these wind codes and standards. This paper compares wind-induced building responses estimated from CFD analysis and those obtained using major international wind codes: AS/NZS1170.2:2011 (Australia/New Zealand), AIJ-RLB-2004 (Japan) and Eurocode-2005 (Europe), with HFBB predictions. The initial comparison was done on a rectangular 60-storey building model and subsequently, the study was extended to building models with different $b / d$ ratios (breadth/depth) under three height categories. The results show that there are minor discrepancies between the code-predicted alongwind responses and those obtained using different approaches with different $b / d$ ratios. Moreover, the across-wind responses predicted by the wind codes significantly deviate from the HFBB results, especially when the wind direction is normal to the shorter face of the building. The deviations intensify as the $\mathrm{b} / \mathrm{d}$ ratio decreases. Nevertheless, the CFD predictions correspond well with the HFBB predictions for along-wind responses having deviations under 10\%, highlighting the capability of CFD simulation for predicting global wind-induced responses of tall buildings.
\end{abstract}

Keywords: $\quad$ Tall Buildings, Wind Loads, Wind codes, Computational Fluid Dynamics

\section{Introduction}

As buildings become taller their sensitivity to wind loads increases. Therefore, an accurate determination of the wind-induced building response is necessary to ensure safe and economical designs. Several wind codes have been developed to predict building responses to wind loads. Although they share a common theoretical basis, the results obtained from using these different wind codes have observable differences. Furthermore in general, the applicability of wind codes is limited to regular-shaped structures with a height not exceeding $200 \mathrm{~m}$ with the first mode natural frequency exceeding $0.2 \mathrm{~Hz}$ [1], [2].

The wind response of a building will consists of along-wind, across-wind and torsional components. The along-wind response comprises mean and dynamic components. Gust Loading Factor (GLF) approach is used in most international codes and standards to assess the dynamic component [3]. The acrosswind response, which is more likely to arise from vortex shedding, has not been sufficiently addressed in many of the international wind codes [4]. As across-wind excitation mechanisms are more complex, the random excitation model, which is based on the random vibration theory, is utilized for predicting the across-wind response of buildings [5]. Although most codes use a random vibration based gust loading factor approach for assessing the dynamic along-wind response of buildings, different codes define different parameters with minor deviations among them [6], [7]. In addition, wind codes also provide different provisions for the calculation of across-wind response [8]. Not many wind codes address the torsional response of buildings.

A number of studies have been conducted to assess the consistency of international wind

Eng. H.M.A.D. Jayasundara, B.Sc. Eng. (Hons.) (Peradeniya), Department of Civil Engineering, University of Peradeniya

Email:dilharajayasundara@gmail.com

ORCID ID: http://orcid.org/0000-0002-6861-9948

Eng. S.M.N.H. Koliyabandara, B.Sc. Eng. (Hons.) (Peradeniya), Department of Civil Engineering, University of Peradeniya

Email:nipunkoliyabandara@gmail.com

ORCID ID: http://orcid.org/0000-0002-1895-3171

Eng. (Dr.) K.K. Wijesundara, B.Sc. Eng. (Hons.) (Peradeniya), M.Sc. (Pavia), Ph.D. (Pavia), Senior Lecturer in Civil Engineering, Department of Civil Engineering,

University of Peradeniya

Email:kushanw@pdn.ac.lk

ORCID ID: http://orcid.org/0000-0002-4174-8707 
codes and standards. A set of 15 wind codes have been used in the study conducted by Holmes et al. [9] to determine the wind response of three buildings of different heights. The study reveals that the across-wind acceleration is greater than the along-wind acceleration. Furthermore, the study shows that as the building height increases, the coefficient of variation of the results decreases despite the increased complexity associated with the building height.

In the study conducted by Kwon and Kareem [8], it has been revealed that a significant portion of the deviations observed in the wind responses calculated using different wind codes can be attributed to the differences in the wind velocity profiles. The study has proposed the use of a common velocity pressure at the top of the building for all wind codes to be able to compare them better. The gust factor for the wind velocity pressure has been used to account for the difference in averaging times. The study concludes that even though there are discrepancies among the parameters used by different wind codes, there is a reasonable consistency in the along-wind response, although there is a significant scatter in the across-wind response.

Eurocode has been identified to be overpredicting wind loads due to the use of division-by-parts rule, which imposes higher loads at the lower parts of the building [10]. This results in higher base shear and base bending moments. Therefore, it is advisable to choose smaller strips rather than larger ones at intermediate levels, to minimize the adverse effects on base bending moments.

However, it is noted that the studies conducted for assessing the consistency of international wind codes have fairly overlooked the effects of $\mathrm{b} / \mathrm{d}$ (breadth/depth) ratio on building response predictions. Therefore, this study focuses mainly on the effects of $b / d$ ratio on wind code predictions of along-wind and across-wind responses of buildings: base shear, base moment and storey force distribution. Eurocode[1], Japanese code (AIJ) [11] and Australian and New Zealand standards (AS/NZS) [2]were used as code-based approaches in this study.

Furthermore, High-Frequency Base Balance (HFBB) data analysis [12], which is based on the American Society of Civil Engineers' standard (ASCE) [13], has emerged as a promising database-enabled design procedure which is based on wind tunnel-derived data (nondimensional base bending moment spectra). Since HFBB data analysis is an experimental method, it is being used as a reference to evaluate the predictions of code based design approaches.

During the past few decades, the use of Computational Fluid Dynamics (CFD) to simulate wind conditions around buildings and structures and thereby determine wind loads imposed on them has become popular, mainly due to the enhancement of computational capacity [14]-[17]. This has, to a certain extent, replaced the necessity to conduct physical wind tunnel tests on tall buildings. Physical wind tunnel tests are more expensive and have limitations with regard to scaling. In the preliminary design of tall buildings, it is important that the building geometry is designed to be aerodynamically advantageous, in order to minimize the adverse effects of wind-induced vibrations. This optimum building geometry can be achieved easily through CFD rather than by conducting physical wind tunnel tests on several models.

However, the consistency of CFDanalysis, which uses conventional design approaches, has still not been firmly established. Therefore, this study further evaluates the applicability of CFD for determining wind-induced responses of buildings with respect to HFBB data analysis and code-based approaches. However, due to the difficulty of modelling building vibrations, CFD is not used to determine across-wind responses.

To achieve the above mentioned objectives, the wind-induced response of a 60-storey building was determined as an initial comparison using the approaches mentioned, for survivability design and serviceability requirements in along-wind and across-wind directions. The torsional component of the wind response has been ignored in this study. The comparison was subsequently extended to building models with different aspect ratios (width: length: height) in order to have a comprehensive understanding of the consistency of wind codes including their dependence on the $b / d$ ratio.

\section{Wind Speed and Load Characteristics}

Different codes and standards use different averaging times for the basic wind velocity $\left(\mathrm{V}_{0}\right)$ and wind-induced response. ASCE and AS/NZS, in particular, define the basic velocity 
as the 3-second gust speed, whereas AIJ and Eurocode use the 10-minute mean wind speed at a reference height of $10 \mathrm{~m}$. In determining the wind-induced response, ASCE utilizes the 1-hr average, whereas AS/NZS, AIJ and Eurocode use the 10-minute average. In this study, a 50year return period was considered for the survivability design and a 10 -year return period was used for the serviceability design.

Wind speed is determined based on the geographic location of a building. Wind velocity profile is largely influenced by the type of terrain. The vertical variation of wind velocity is described by either a power law or a logarithmic law. ASCE and Eurocode use the power law to calculate the velocity profile.

$$
V(z)=b\left(\frac{z}{10}\right)^{a} V_{0}
$$

The constants $b$ and $a$ in Eq.1, depend on the terrain category and averaging time, and $z$ is the height of interest. $V_{0}$ is the basic reference wind velocity at a height of $10 \mathrm{~m}$ above ground. AIJ and AS/NZS use the logarithmic law, the general form of which is given in Eq. 2 .

$$
V(z)=c \ln \left(\frac{z}{z_{0}}\right) V_{0}
$$

The constant $c$ and the roughness length $z_{0}$ depend on the terrain category. Due to the differences in the two definitions and the constants used, velocity profiles developed by different wind codes will not be consistent.

\section{Wind-induced Responses of Tall Buildings}

When there are dynamic wind loads, tall buildings will oscillate in three directions: along-wind, across-wind and torsional. Torsional response becomes dominant in asymmetric structures when it gets coupled with a translational mode. However, as most wind codes do not indicate how to calculate the torsional response, it had to be ignored in this study.

\subsection{Along-wind Response}

Along-wind response is primarily caused by pressure fluctuations on the windward and leeward faces of the building, which generally follow fluctuations of the approach flow in the low-frequency range [18]. For buildings having a significantly large depth compared to the breadth, the friction generated on the side walls could form a considerable portion of the alongwind force [1], [2].

The general expression for along-wind pressure $\left(P_{z}\right)$ on a building is given in Eq. 3 [8].

$$
P(z)=q(z) G C_{p}
$$

where $q(z), G$ and $C_{p}$ are the velocity pressure at a height of $z$, gust effect factor and the pressure coefficient respectively. Storey forces and bending moments can be calculated by multiplying the wind pressure respectively by the relevant tributary areas and multiplying the forces by the respective heights. Base shear and base bending moment can be calculated by the summation of the forces and bending moments at each level. The general expression for the velocity pressure is given in Eq. 4 .

$$
q(z)=\frac{1}{2} \rho V_{m}^{2}(z)
$$

where $\rho$ is the air density and $V_{m}(z)$ is the mean velocity at a height of $z$ which is determined by factoring the basic wind velocity for the effects of exposure, topography, wind direction, shielding and terrain/height. However, there are differences among the wind codes in the calculation of the velocity pressure. In AIJ, the mean velocity and velocity pressure at the top of the building are taken as constants. The pressure coefficient is varied with the building height to incorporate the vertical variation of velocity. In the other wind codes, the pressure coefficient $\left(C_{p}\right)$ is kept constant while changing the mean velocity and velocity pressure with the building height.

The gust effect factor $(G)$ may be written in a general format as given in Eq. 5 [3], [19].

$$
G=\frac{G L F}{G_{q}}
$$

WhereGLF is the gust loading factor for the displacement and $G_{q}$ is the gust factor for the wind velocity pressure. Eq. 5 accounts for the difference in the averaging times between the wind velocity and the wind-induced response or pressure which can be defined as given in Eq. 6 given below.

$$
G_{q}=2 G_{v}-1=1+g_{v}
$$

where $G_{v}$ and $g_{v}$ are the gust factor and peak factor for the wind velocity respectively. $G_{v}$ is defined as the ratio of the mean velocities based on the averaging time for the velocity and for 
the wind-induced response. In AIJ, $G_{q}$ is taken as equal to unity since the 10-minute averaging time is taken for both the wind velocity and wind response.

Among the wind codes, there is a difference in the terminology used for the gust effect factor with AS/NZSusing the term dynamic response factor and Eurocode using the term structural factor. GLFwhich was originally defined by Davenport [6]can generally be expressed as follows [8].

$$
G L F=1+r \sqrt{g_{B}^{2} B+g_{R}^{2} R}
$$

where $g_{B}$ and $g_{R}$ are the peak factors for background and resonance responses respectively; $B$ and $R$ are the background and resonance factors respectively. $r$ is given as follows by Eq. 8 .

$$
r=2 I_{z}
$$

where $I_{z}$ is the turbulence intensity. It should be noted that ASCE uses a factor of 1.7 instead of 2 and AIJ uses a factor ranging from 2.13 to 2.418 based on the exposure category [8]. ASCEAIJ and AS/NZS use power law to define the turbulence intensity profile, the general form of which is given in Eq. 9.

$$
I(z)=d\left(\frac{z}{10}\right)^{\beta}
$$

where $d$ and $\beta$ are variables related to the exposure category [8]. Eurocode has adopted a logarithmic relationship as given in Eq. 10[1].

$$
I(z)=\frac{k_{I}}{C_{0}(z) \ln \left(\frac{z}{z_{0}}\right)}
$$

where $k_{I}$ is the turbulence factor, the recommended value of which is 1.0. $C_{o}(z)$ is the orography factor and $z_{0}$ is the roughness length defined based on the terrain category.

The background response factor $(B)$ is defined as a function of the building dimensions and the turbulence length scale $(L)$, but the definition varies substantially among wind codes. The resonance factor $(R)$ is a function ofthe size reduction factor $(S)$, energy factor $(E)$ and the critical damping $\operatorname{ratio}(\zeta) . R$ also has considerable variations among the wind codes. A general expression for the resonance factor $(R)$ is given in Eq. 11 [8].

$$
R=\frac{\pi S E}{2 \zeta}
$$

However, this expression differs from the Equation given in the Eurocode(Eq. 12).

$$
R=\frac{\pi S E}{2 \zeta}
$$

For the comparisons done in the latter part of this study, Eq. 12 was used since it is consistent with the high damping values recommended in Eurocode for reinforced concrete buildings. A comparison of the different formulae given in the wind codes to calculate these parameters is presented in Table 1.

\subsection{Across-wind Response}

Across-wind response is caused by pressure fluctuations on the side faces of the building which are influenced by separated shear layers and wake dynamics [20]. The most common source of cross-wind excitation is wake excitation associated with vortex shedding [4], [5]. Even though, the dynamic along-wind response can be predicted with reasonable accuracy using the gust factor approach, the across-wind excitation mechanisms have proven to be much more challenging to obtain [5]. There are several models that can be used to determine the across-wind response of the buildings based on the random vibration theory [5].

Out of the three wind codes used in this study, only AS/NZS and AIJ have provisions to calculate the across-wind response of a building. Eurocode does not provide a procedure to calculate the across-wind response other than the provisions made in it to incorporate the effect of vortex shedding. The equivalent static across-wind force $\left(W_{e q}\right)$ can be calculated according to AS/NZS using Eq. 13.

$$
W_{e q}(z)=0.5 \rho_{\text {air }}\left[V_{\text {des } \theta}\right]^{2} d C_{f i g} C_{d y n}
$$

where $V_{d e s \theta}, d, C_{f i g}$ and $C_{d y n}$ are the design wind velocity at the building height, horizontal depth of the building parallel to the wind stream, aerodynamic shape factor and dynamic response factor respectively. The expression for $C_{f i g} C_{d y n}$ is given in Eq. 14.

$$
C_{f i g} C_{d y n}=1.5 g_{R}\left(\frac{b}{d}\right) \frac{K_{m}}{\left(1+g_{v} I_{h}\right)^{2}}\left(\frac{z}{h}\right)^{k} \sqrt{\frac{\pi C_{f s}}{\zeta}} \ldots
$$


where $b, h, z, K_{m}, I_{h}, C_{f s}$ and $\zeta$ are the breadth of the building normal to the wind direction, building height, height of interest, mode

Table 1 - Comparison of wind code parameters

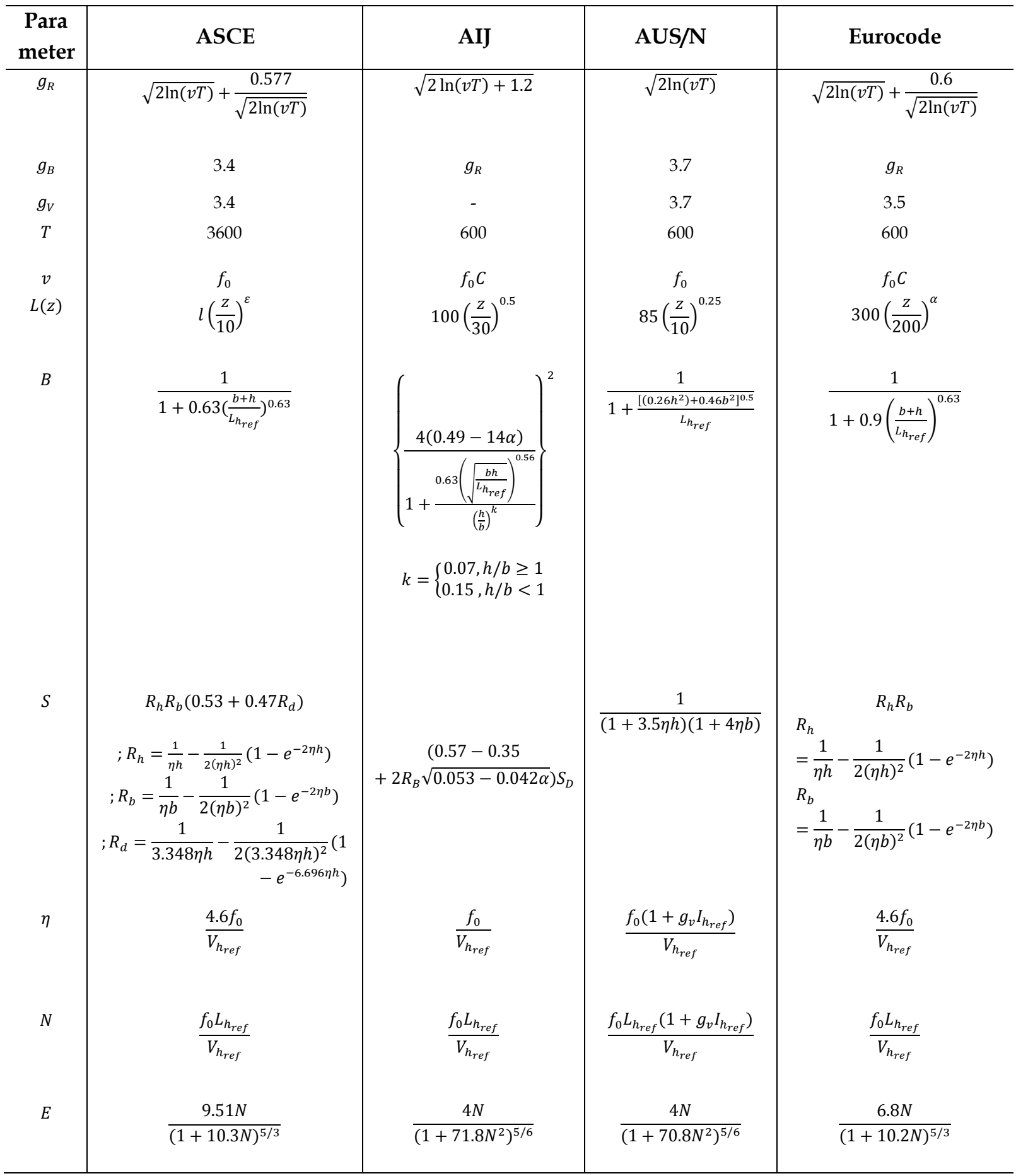

shape correction factor, turbulence intensity factor, across-wind spectrum coefficient generalized for the linear mode shape and critical damping ratio respectively.

In AIJ, the wind load caused by across-wind vibration is calculated using Equation 15. where $q_{h}, A, z, h, \emptyset_{L}$ and $R_{L}$ are the velocity pressure at roof level, projected area, height of interest, building height, correction coefficient for the vibration mode and resonance factor respectively. $C_{L}^{\prime}$ is defined as a function of $\mathrm{b} / \mathrm{d}$ ratio in Eq. 16. 


$$
\begin{aligned}
& W_{L}(z)=3 q_{h} C_{L}^{\prime} A \frac{z}{h} \sqrt{1+\varnothing_{L}^{2} R_{L}} \\
& C_{L}^{\prime}=0.0082\left(\frac{d}{b}\right)^{3}-0.071\left(\frac{d}{b}\right)^{2}+0.22\left(\frac{d}{b}\right)
\end{aligned}
$$

AS/NZS uses in Eq. 14 b/d ratio for calculating across wind load whereas AIJin Eq. 16 uses d/b (depth/breadth) ratio. This conflicting use of the $b / d$ ratio is a crucial factor when these the two wind codes are compared for models with different $b / d$ ratios.

\subsection{Peak Acceleration}

Tall buildings are designed in terms of their acceleration response to ensure human comfort and safety by considering not only the survivability conditions but also the serviceability conditions. A peak acceleration of less than $5 \mathrm{mg}$ is not perceptible to humans and anything beyond $150 \mathrm{mg}$ is intolerable [21]. All the wind codes used in this study have provisions to calculate along-wind acceleration, whereas only AIJ, AS/NZS and HFBB analysis provide a method to calculate across-wind acceleration. The general expression for alongwind acceleration is given in Eq. 17 [8].

$$
\hat{\ddot{x}}(z)=\frac{q_{h_{r e f}} G_{R} C_{f x} b h K}{m_{1}} \emptyset_{1}(z)
$$

where $q_{h_{r e f}}, C_{f x}, b, h, K$, and $m_{1}$ are the reference velocity, dag force coefficient given by the absolute sum of the windward and leeward pressure coefficients, building breadth, building height, mode shape correction factor, and generalized mass in the first mode respectively. $\emptyset_{1}(z)$ is the first mode shape evaluated at aheight of $z . G_{R}$ is defined in Table 1. The across-wind acceleration can generally be defined using Eq. 18 given below[8].

$$
\widehat{\ddot{y}}(z)=\frac{\widehat{M}_{R} K_{y}}{m_{0} h^{2}} \emptyset_{1}(z)
$$

where $\widehat{M}_{R}$ is the resonant component of the across-wind moment, $K_{y}$ is the mode shape correction and $m_{0}$ is the mass per unit height.

\section{High-frequency BaseBalance Data Analysis}

Zhou et al. [22] suggest that the guidance provided for the calculation of across-wind and torsional responses in the codes of practice currently used is inadequate. To address this, an interactive database of high frequency base balance measurements taken in a set of isolated tall buildings has been developed[12]. The maximum expected base bending moment $(\widehat{M})$ in along wind and across wind directions or base torque is expressed in Eq. 19.

$$
\hat{M}=\bar{M}+g \times \sigma_{M} \approx \bar{M}+\sqrt{M_{B}^{2}+M_{R}^{2}} .
$$

where $\bar{M}, g, \sigma_{M}, M_{B}$ and $M_{R}$ are the mean moment, peak factor, Root Mean Square (RMS) of the fluctuating base moment/torque response, background and resonant base moment or torque component respectively. As given in Eq. 19, the maximum response is calculated by the addition of the mean response and the product of peak factor and RMS of the fluctuating response. The RMS of the fluctuating base moment/torque response is calculated using Eq. 20[22].

$$
\sigma_{M}=\left(\int_{0}^{\infty} S_{M}(f) d f\right)^{1 / 2}
$$

The Power Spectral Density (PSD) $\left(S_{\boldsymbol{M}}(f)\right)$ of the moment/torque response is given in Eq. 21.

$$
S_{M}(f)=S_{M}(f)\left|H_{1}(f)\right|^{2}
$$

where $S_{M}(f)$ is the PSD of the external base moment/torque and $\left|H_{1}(f)\right|^{2}$ is the structural first mode transfer function given in Eq. 22.

$$
\left|H_{1}(f)\right|^{2}=\left\{\left[1-\left(\frac{f}{f_{1}}\right)^{2}\right]^{2}+\left(2 \zeta_{1}\left(\frac{f}{f_{1}}\right)\right)^{2}\right\}^{-1} \ldots
$$

where $f$ is frequency, $f_{1}$ is the natural frequency of the first mode in the direction of motion and $\zeta_{1}$ is the building damping ratio in the first mode. To simplify computations, integration is divided into background and resonant components. These two components can be computed using Eq. 23 and Eq. 24 [12].

$$
\begin{aligned}
& M_{B}=g_{B} \sigma_{C M} \bar{M}^{\prime} \\
& M_{R}=g_{R} \sigma_{C M} \bar{M}^{\prime} \sqrt{\frac{\pi}{4 \zeta_{1}} C_{M}\left(f_{r 1}\right)}
\end{aligned}
$$


where $g_{B}$ and $g_{R}$ are the peak factors for background and resonant components respectively. $\overline{M^{\prime}}$ is the reference moment/torque depending on the response component, while $\sigma_{C M}$ is the base moment/torque response coefficient $\left(=\sigma_{M} / \overline{M^{\prime}}\right) \cdot C_{M}\left(f_{r 1}\right)$ is the nondimensional moment coefficient at $f_{r 1}\left(=f_{r 1} \times\right.$ $\left.S_{M}\left(f_{r 1}\right) / \sigma_{M}^{2}\right)$, where $f_{r 1}$ is the reduced frequency according to natural frequency $f_{1}$ in the direction of motion and $S_{M}(f)$ is the PSD of the fluctuating base moment or torque.

\section{Numerical Simulation}

Over the past few decades, computational wind engineering has made a rapid growth as a branch of Computational Fluid Dynamics (CFD) to numerically evaluate wind-structure interactions, as an alternative technique to code-based design procedures. Wind flow around bluff bodies is governed by incompressible Navier-Stokes Equations and continuity Equations. The Reynolds-Averaged Navier-Stokes Equations (RANS) Model, which was obtained by averaging the original Equations over time, is widely used as a CFD technique for predicting wind flows around bluff bodies. The Large Eddy Simulation (LES) Model which is based on filtered Navier-Stokes Equations is also used in CFD but is limited in applicability due to the high computational power requirements[15], [23].

The appearance of additional terms called Reynolds stresses in the RANS Equations adds to the complexity and makes direct analysis impossible to perform. Therefore, various types of turbulence models are used to ease computation. Among these models, the two Equation $\mathrm{k}-\epsilon$ turbulence model is widely used in wind engineering problems because of thegood reputation it has for reliability [15].However, in the case of wind flowing around sharp-edged bluff bodies, there are many difficulties which are not found in the usual CFD computations for simple flows [24]. To overcome these difficulties, revisions of the RANS model, especially for the standard $\mathrm{k}-\epsilon$ model, such as the LK Model [25] and the MMK Model [26] have been proposed lately.

\section{Initial Comparison}

\subsection{Building Model}

The initial comparison was performed on a rectangular shaped building with a length $\left(D_{x}\right)$, width $\left(\mathrm{D}_{\mathrm{y}}\right)$ and height $(\mathrm{H})$ of $56 \mathrm{~m}, 26 \mathrm{~m}$ and $198 \mathrm{~m}$ respectively. Natural frequencies for the two dominant translational modes were taken as $0.21 \mathrm{~Hz}$ and $0.24 \mathrm{~Hz}$ in the directions normal to the long face and short face respectively. Linear mode shapes were assumed for all three modes of vibration. Mass density of the building and air density were taken as 520 $\mathrm{kg} / \mathrm{m}^{3}$ and $1.25 \mathrm{~kg} / \mathrm{m}^{3}$ respectively. Damping coefficient was taken as 0.1 for the Eurocode and as 0.03 for all other wind codes according to the values specified for reinforced concrete buildings [1], [2].

\subsection{Computational Model}

CFD simulation was done with a full-scale model of the building using Midas NFX software. Fluid domain was taken sufficiently large in order to eliminate the effect of boundaries on the flow inside it. The fluid domain was divided into five subdomains to input the anticipated inlet velocity profile of the terrain. Boundary conditions of the fluid domain were set to no-slip boundary condition at the surface of the building, inviscid wall condition and zero normal velocity flux for all other surfaces which are parallel to the airflow and atmospheric pressure at the outlet. The dimensions of the fluid domain are given in Figure 1.
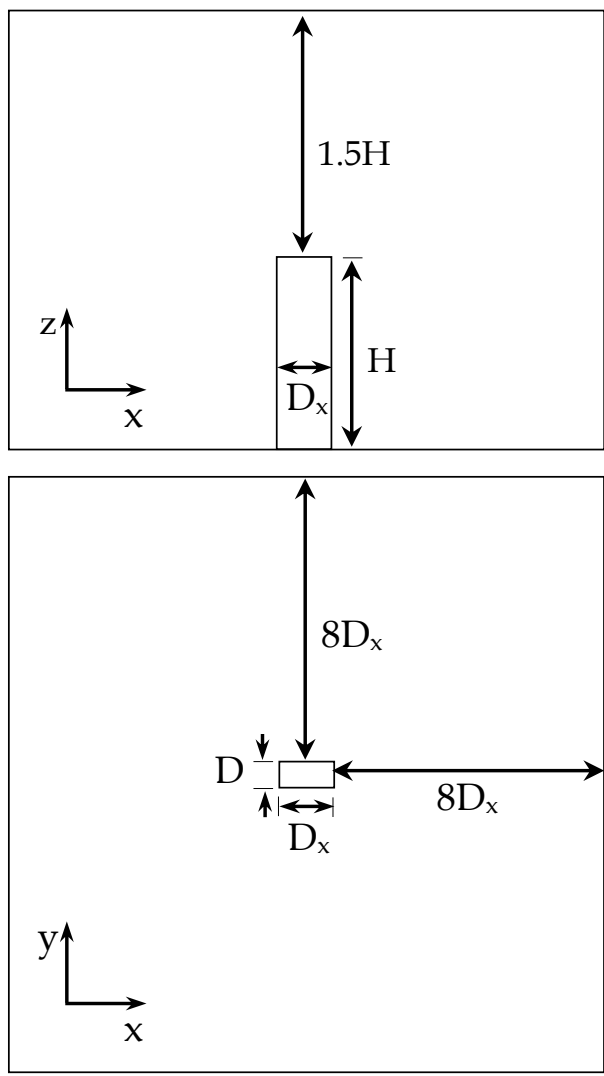

Figure 1 - Computational domain.

Mass density and viscosity of air were taken as $1.25 \mathrm{~kg} / \mathrm{m}^{3}$ and $1.79 \times 10^{-5} \mathrm{~kg} / \mathrm{ms}$ respectively. A very fine grid resolution was used in the nearwall regions of the building in order to accurately model the separated boundary layer 
flow. The fluid subdomains were meshed separately using tetrahedral elements and considering the geometric proximity, mesh pattern and independent mesh registration. Grid density was increased in proximity to the building walls [27]. The subdomains were then merged together. The element size growth rate was fixed at 1.05 whereas the ratio of minimum to maximum element size was kept at 2 . The number of elements in the generated mesh shown in Figure 2 was $3.7 \times 10^{5}$.

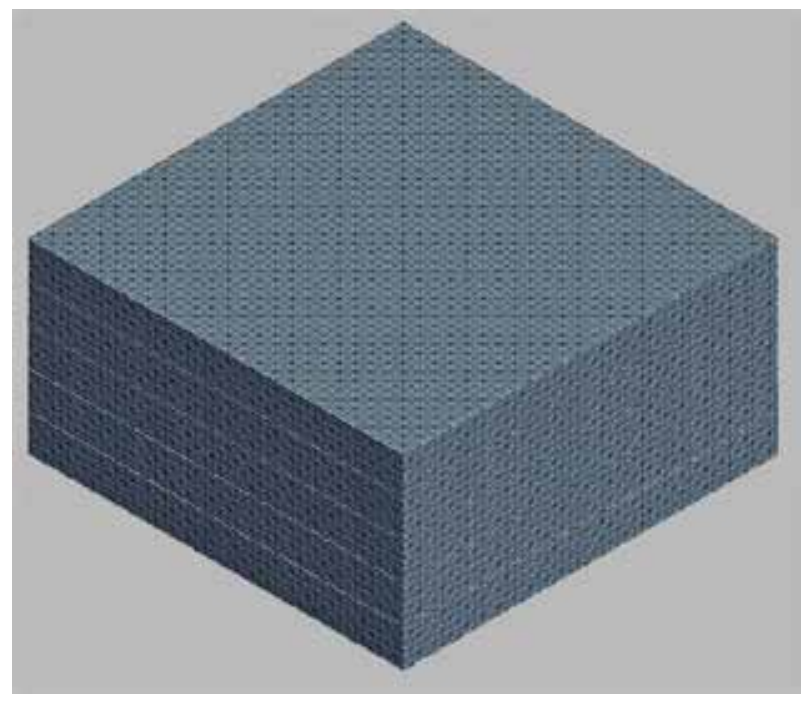

(a)

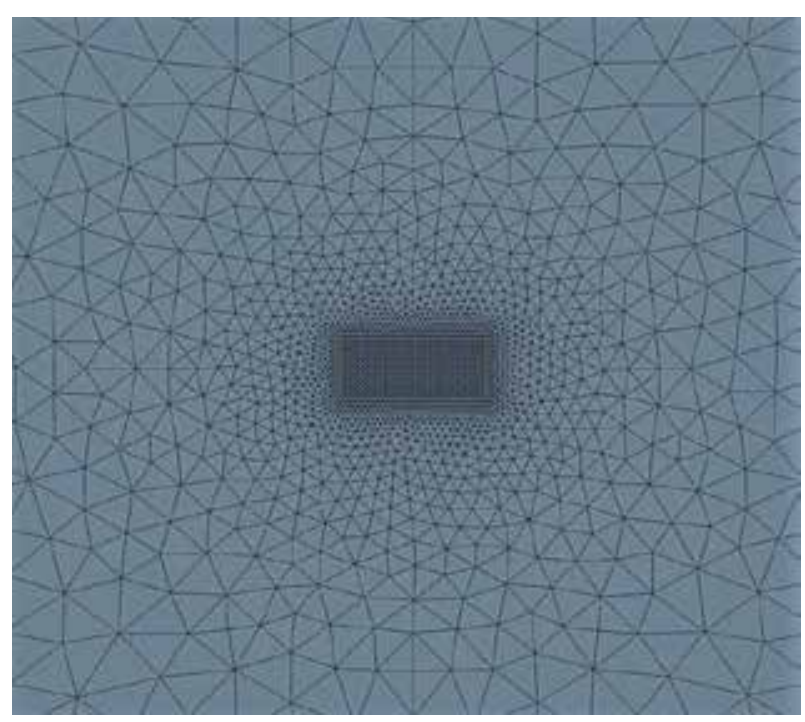

(b)

Figure 2 - Mesh generation: (a) overall view (b) plan view

Since this study was focused on determining the overall pressure distribution of abuilding rather than the local effects, the 2 Equation $k-\varepsilon$ turbulence model was selected. This model has a good reputation for efficiency in computation and has easy implementation. A steady-state CFD analysis was performed considering the limited computational capacity available, and taking the velocity profile as same as that taken for the HFBB data analysis.

\subsection{Comparison of CFD Simulation and Code-based Approaches with HFBBData Analysis}

As the primary comparison, a 3-second wind velocity of $38 \mathrm{~m} / \mathrm{s}$ was used assuming the building was located in an urban exposure category, which is represented by the terrain category- 4 in AS/NZS, AIJ and Eurocode. The factors accounting for topology, wind direction and season were assumed to be unity. The equivalent wind velocities under 10-minute and 1-hour averaging times were obtained as defined in the wind velocity spectrum based method using the conversion factors , 1.46 and 1.53 respectively[19]. To eliminate the differences in velocity profiles that cause a significant part of the deviations, a common velocity pressure was used in all approaches utilizing the gust factor for velocity pressure to convert between different averaging times. The velocity profiles of the design approaches are given in Figure 3 . The modified velocity profiles show considerable consistency among them. Force coefficient based approach was used to calculate the response in Eurocode, as the pressure coefficients have not been defined for building heights exceeding five times the depth of the building.

The building response was determined under both survivability and service ability conditions. Along-wind and across-wind storey-force distribution, base shear, base bending moment and peak acceleration were calculated for the two wind directions: normal to the long face and the short face. Base shear and base bending moment calculated using the five approaches are given in Table 2. Note that both Eurocode and CFD have not been used to determine across-wind responses.

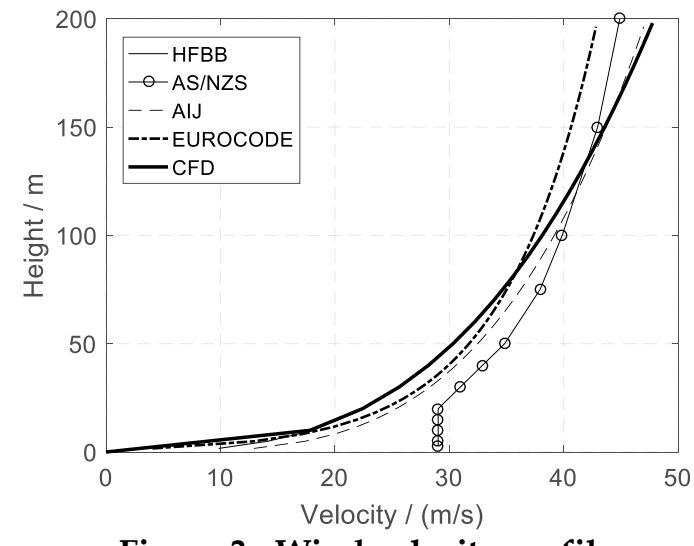

Figure 3 - Wind velocity profiles. 
Table 2 - Base shear and base bending moment results

\begin{tabular}{|c|c|c|c|c|c|c|c|c|}
\hline \multirow{4}{*}{ Code/standard } & \multicolumn{4}{|c|}{ Base shear / MN } & \multicolumn{3}{c|}{ Base bending moment / MNm } \\
\cline { 2 - 9 } & $\begin{array}{c}\text { Wind normal to } \\
\text { long face }\end{array}$ & \multicolumn{2}{c|}{$\begin{array}{c}\text { Wind normal to } \\
\text { short face }\end{array}$} & \multicolumn{2}{c|}{$\begin{array}{c}\text { Wind normal to } \\
\text { long face }\end{array}$} & \multicolumn{2}{c|}{$\begin{array}{c}\text { Wind normal to } \\
\text { short face }\end{array}$} \\
\cline { 2 - 9 } & $\begin{array}{c}\text { Along- } \\
\text { wind }\end{array}$ & $\begin{array}{c}\text { Across- } \\
\text { wind }\end{array}$ & $\begin{array}{c}\text { Along- } \\
\text { wind }\end{array}$ & $\begin{array}{c}\text { Across- } \\
\text { wind }\end{array}$ & $\begin{array}{c}\text { Along- } \\
\text { wind }\end{array}$ & $\begin{array}{c}\text { Across- } \\
\text { wind }\end{array}$ & $\begin{array}{c}\text { Along- } \\
\text { wind }\end{array}$ & $\begin{array}{c}\text { Across - } \\
\text { wind }\end{array}$ \\
\hline HFBB & 10.5 & 3.8 & 4.9 & 5.0 & 1305.9 & 508.8 & 618.2 & 666.0 \\
AS/NZS & 12.2 & 3.3 & 5.8 & 2.7 & 1375.2 & 440.3 & 659.6 & 362.5 \\
AIJ & 13.0 & 4.4 & 5.4 & 6.4 & 1402.8 & 584.8 & 590.5 & 839.7 \\
Eurocode & 14.8 & - & 6.5 & - & 1595.4 & - & 721.9 & - \\
CFD & 11.1 & - & 4.7 & - & 1241.9 & - & 568.4 & - \\
\hline
\end{tabular}

Table 3 provides for the base shear forces and base bending moments the percentage deviation of CFD results from the corresponding HFBB predictions. The maximum deviation is $8.1 \%$ and thus it can be concluded that CFD can be used with adequate accuracy to simulate the along-wind response of a building.

Table 3 - Deviation of CFD result from HFBB value for base shear and base bending moment

\begin{tabular}{|l|c|c|}
\hline \multicolumn{1}{|c|}{$\begin{array}{c}\text { Wind induced } \\
\text { response }\end{array}$} & \multicolumn{2}{|c|}{ Deviation $/ \%$} \\
\cline { 2 - 3 } & $\begin{array}{c}\text { Wind on } \\
\text { long face }\end{array}$ & $\begin{array}{c}\text { Wind on } \\
\text { short face }\end{array}$ \\
\hline $\begin{array}{l}\text { Base shear } \\
\begin{array}{l}\text { Base bending } \\
\text { moment }\end{array}\end{array}$ & 5.7 & -4.1 \\
\hline
\end{tabular}

The consistency of the design approaches can be visualized using storey force distributions. The along-wind storey force distributions for wind normal to the long face and short face are given in Figures 4 and 5 respectively.

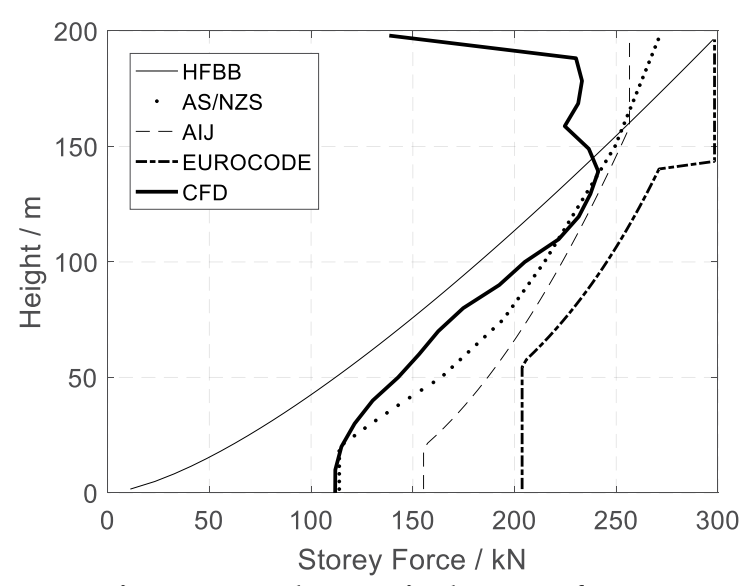

Figure 4 - Along-wind storey force distribution for wind normal to long face

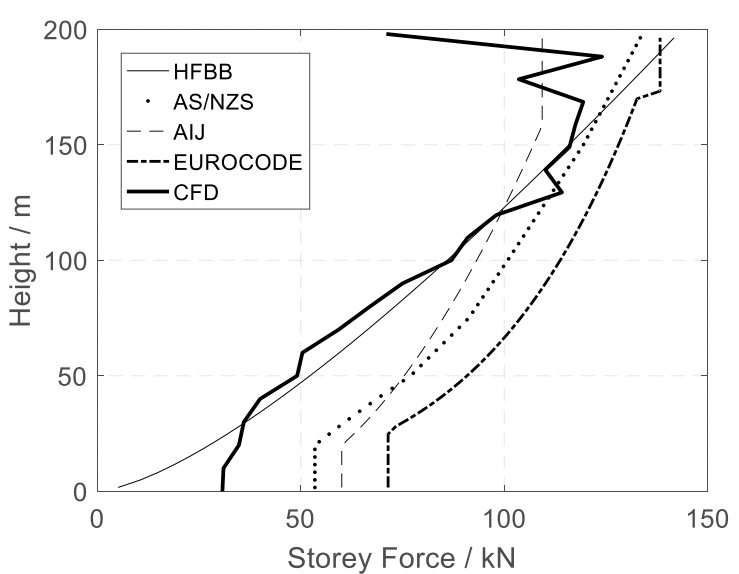

Figure 5 - Along-wind storey force distribution for wind normal to short face

The CFD solution shows a fairly good correlation with the HFBB deviating slightly towards the upper part. This is due to the end effect of the building where the airflow separates out to flow above the building. As a result, a decrease in the pressure can be anticipated. Eurocode predicts a significantly higher value compared to all other approaches which tallies with the observations made by [10]. AIJ value deviates substantially for the wind normal to the long face, but not so much for the wind normal to the short face. This can be attributed to the difference in the leeward pressure coefficient when the $b / d$ ratio changes [11].

Figure 6 illustrates pressure distribution around the building in the plan view for the wind normal to the long face. The pressure difference between windward and leeward faces causes the along-wind load on the building. Lowpressure regions are observed on the side faces of the building closer to the front face indicating the development of vortices. Figure 7 shows the pressure distributions on the front face of the building for wind normal to the long 
face. A high-pressure region is observed towards the top part of the building which is consistent with the force distribution curve and previous studies [27]. Figure 8 illustrates the flow path around the building. Wake vortices form in the leeward side of the building due to the low-pressure regions observed in Figure 6.

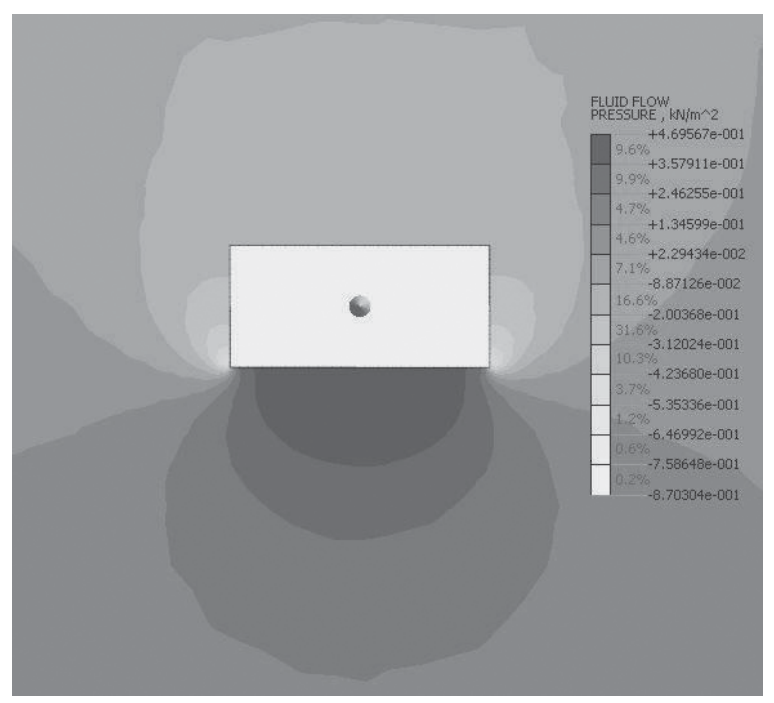

Figure 6 - Pressure distribution around the building for wind normal to long face

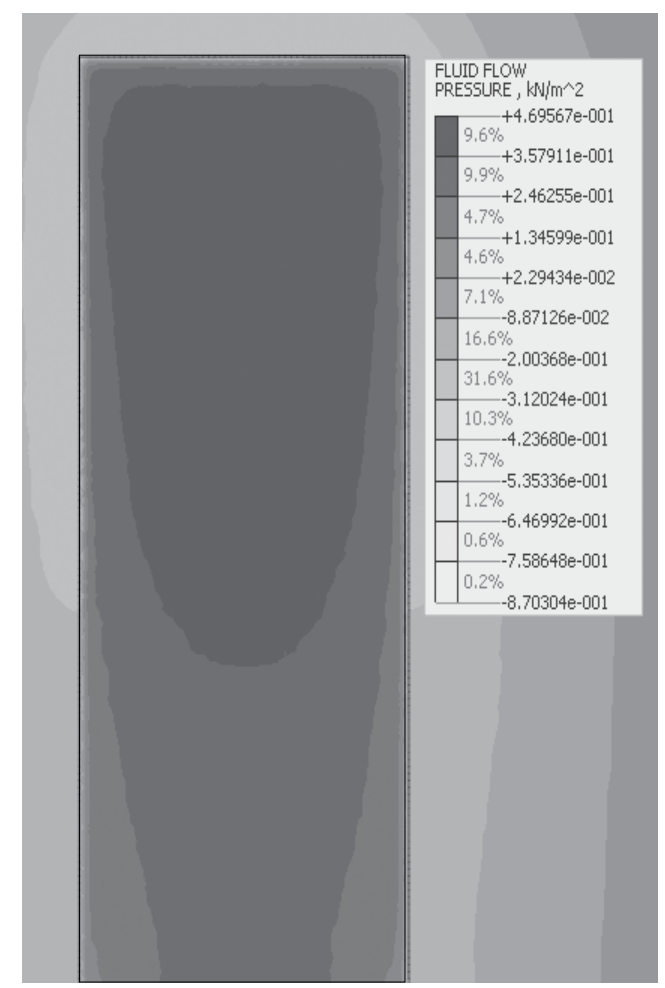

Figure 7 - Pressure distribution on the front face for wind normal to long face

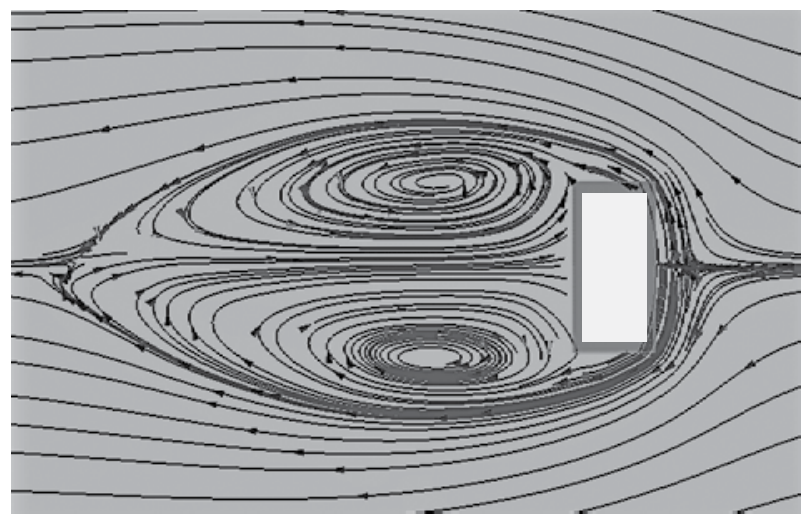

\section{Figure 8 - Flow path for wind normal to long face - plan view}

The across-wind storey force distributions for wind normal to long face and short face are given in Figures 9 and 10 respectively. For wind normal to the long face, the results of the two code-based approaches and HFBB data analysis show a fair correlation, but when wind is normal to the short face, the three approaches display a substantial deviation from one another. AIJ predicts the highest value whereas AS/NZSpredicts the lowest value.

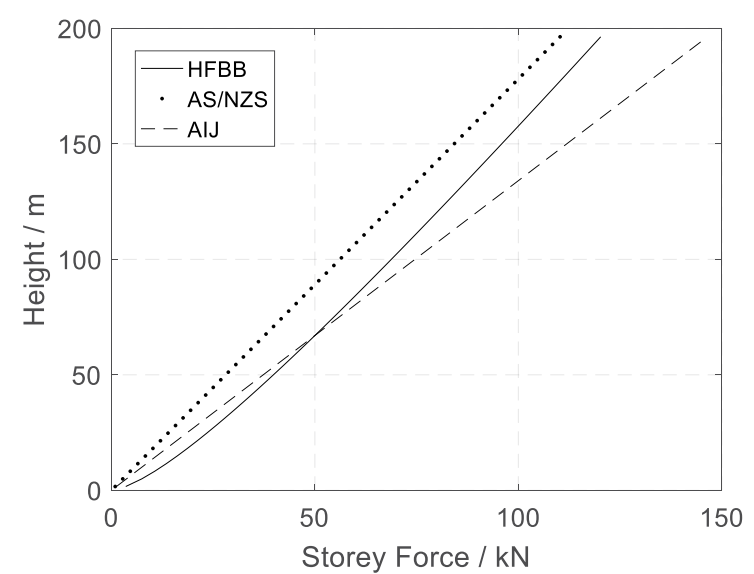

Figure 9 - Across-wind storey force distribution for wind normal to long face

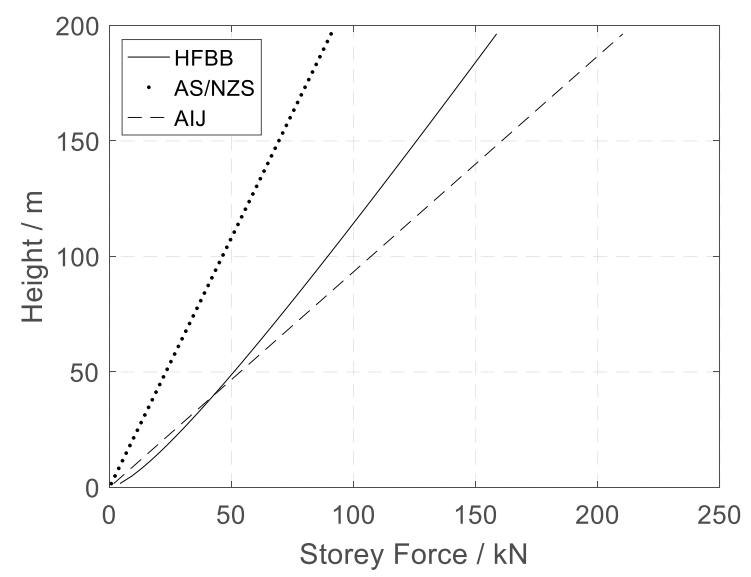

Figure 10 - Across-wind storey force distribution for wind normal to short face 
The along-wind and across-wind peak accelerations calculated using code-based approaches are given in Table 4. HFBB predicts the highest value for along-wind acceleration in both wind directions. The AIJ prediction of the across-wind acceleration is twice the AS/NZS prediction when wind is normal to the short face. A similar discrepancy is found in the force distribution as well.

Table 4 - Peak accelerations

\begin{tabular}{|c|c|c|c|c|}
\hline \multirow{2}{*}{$\begin{array}{c}\text { Peak } \\
\text { accel./ } \\
\text { (mg) }\end{array}$} & \multicolumn{2}{|c|}{$\begin{array}{c}\text { Wind normal } \\
\text { to long face }\end{array}$} & \multicolumn{2}{c|}{$\begin{array}{c}\text { Wind normal to } \\
\text { short face }\end{array}$} \\
\cline { 2 - 5 } & $\begin{array}{c}\text { Along } \\
\text {-wind }\end{array}$ & $\begin{array}{c}\text { Across } \\
\text {-wind }\end{array}$ & $\begin{array}{c}\text { Along } \\
\text {-wind }\end{array}$ & $\begin{array}{c}\text { Across } \\
\text {-wind }\end{array}$ \\
\hline HFBB & 4.0 & 3.5 & 2.1 & 4.2 \\
AS/NZS & 2.4 & 5.4 & 1.6 & 3.8 \\
AIJ & 3.1 & 4.2 & 1.4 & 7.0 \\
Eurocode & 2.5 & - & 1.3 & - \\
\hline
\end{tabular}

Table 5 depicts the coefficients of variation for the different responses calculated using the design approaches. It is clearly observed that for the across-wind responses, the coefficients of variation show a dramatic increase when the wind is normal to the short face of the building. This reveals that there is a discrepancy among the design approaches for the across-wind response when the depth is higher than the breadth of the building. Therefore, to investigate this phenomenon, a detailed investigation was conducted incorporating the $\mathrm{b} / \mathrm{d}$ ratio of the building into the comparison.

\section{Detailed Comparison}

In order to perform an in-depth evaluation of the deviation observed in the initial comparison, the same comparison was extended to a set of building models with different $b / d$ ratios and under three height categories: $132 \mathrm{~m}, 165 \mathrm{~m}$ and $198 \mathrm{~m}$ and having natural frequencies for translational modes of $0.4 \mathrm{~Hz}, 0.3 \mathrm{~Hz}$ and $0.2 \mathrm{~Hz}$ respectively. Building models were developed by changing for each height category the building length while keeping the width constant in order to highlight the effect of $b / d$ ratio.

It should be noted that the breadth (b) and depth (d) of a building are defined as the length of the sides perpendicular and parallel to the wind flow respectively. The dimensions of the models, which are given in Table 6, were selected in order to correspond with the models available in the HFBB database and the $h: b: d$ ratios given in AS/NZS for the cross-wind spectrum coefficient [2].

Table 6 - Details of building models

\begin{tabular}{|c|c|c|c|c|}
\hline $\begin{array}{c}\text { Model } \\
\text { No. }\end{array}$ & $\begin{array}{c}\text { Height } \\
\text { (h) / m }\end{array}$ & $\begin{array}{c}\text { Width } \\
\text { (w) / m }\end{array}$ & $\begin{array}{c}\text { Length } \\
\text { (l) /m }\end{array}$ & $\begin{array}{c}\mathbf{w}: \mathbf{1}: \mathbf{h} \\
\text { ratio }\end{array}$ \\
\hline 1 & 132 & 33 & 33 & $1: 1: 4$ \\
2 & 132 & 33 & 49.5 & $1: 1.5: 4$ \\
3 & 165 & 33 & 33 & $1: 1: 5$ \\
4 & 165 & 33 & 49.5 & $1: 1.5: 5$ \\
5 & 165 & 33 & 66 & $1: 2: 5$ \\
6 & 198 & 33 & 33 & $1: 1: 6$ \\
7 & 198 & 33 & 49.5 & $1: 1.5: 6$ \\
8 & 198 & 33 & 66 & $1: 2: 6$ \\
\hline
\end{tabular}

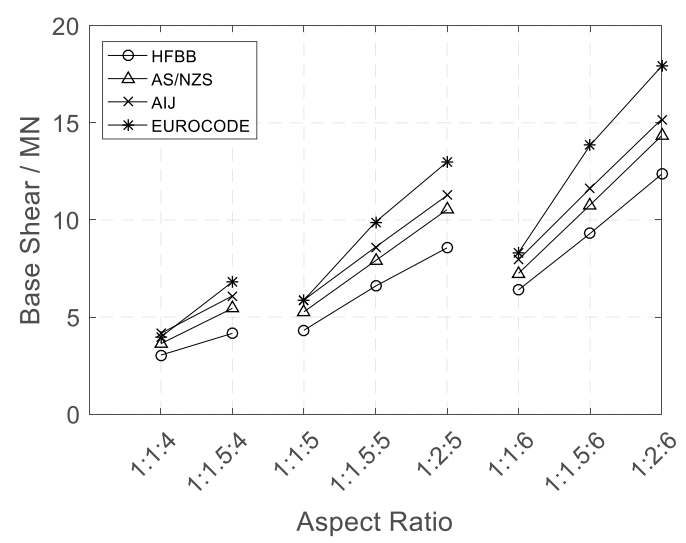

Figure 11 - Along-wind base shear for wind normal to long face

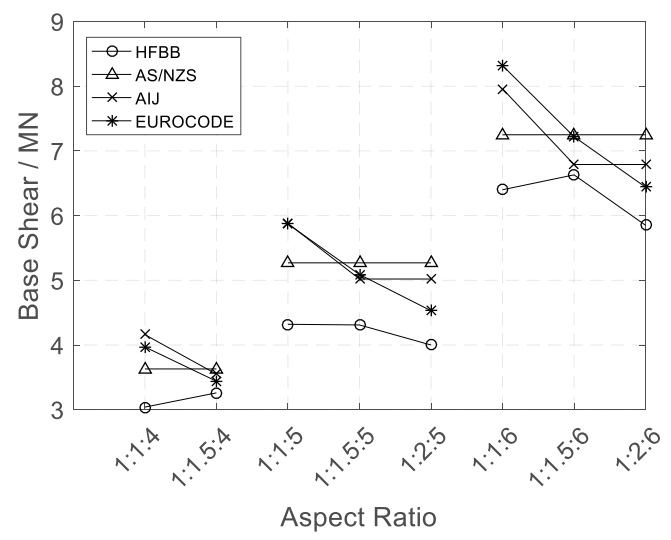

Figure 12 - Along-wind base shear for wind normal to short face

Figures 11 and 12 show the variation of the along-wind base shear forces against the aspect ratio (width:length:height) of the building models when wind blows normal to long and short faces respectively. It should be noted that along the horizontal axis, for each height category, the b/d ratio of the models increases when wind is normal to the long face and that it decreases when wind is normal to the short face. 
Table 5 - Coefficient of variation of building responses

\begin{tabular}{|l|c|c|c|c|}
\hline \multirow{2}{*}{ Parameter } & \multicolumn{2}{|c|}{ Wind on long face } & \multicolumn{2}{c|}{ Wind on short face } \\
\cline { 2 - 5 } & Along-wind & Across-wind & Along-wind & Across-wind \\
\hline Base shear & 0.12 & 0.12 & 0.12 & 0.32 \\
Base bending moment & 0.09 & 0.12 & 0.09 & 0.32 \\
Peak acceleration & 0.21 & 0.18 & 0.18 & 0.29 \\
\hline
\end{tabular}

According to Figure 11, out of the four approaches considered in this study, Eurocode predicts the highest base shear while HFBB predicts the lowerst base shear. Consistancy is observed among the base shear predictions of the four approaches for all three height categories althogh it slightly fades away as the $\mathrm{b} / \mathrm{d}$ ratio of the building increases. However, when wind is normal to the long face, the change of breadth overshadows the effect of the $\mathrm{b} / \mathrm{d}$ ratio.

In Figure 12, the effect of the b/d ratio is clearly visible as the breadth remains constant for different $b / d$ ratios. Therefore, for each height category, base shear force should remain constant unless it is a function of the $\mathrm{b} / \mathrm{d}$ ratio. AS/NZS prediction varies only with height whilestaying constant with the change of the $\mathrm{b} / \mathrm{d}$ ratio. AIJ also predicts a constant lower value for buildings with a $\mathrm{b} / \mathrm{d}$ ratio less than 1 . This is due to the reduction of the leeward pressure coefficient from -0.35 to -0.5 when the depth of the building becomes equal to its breadth. However, Eurocode prediction constantly decreases as the building depth increases since the force coefficient depends linearly on the $b / d$ ratio of the building. The HFBB prediction stays nearly constant upto a $\mathrm{b} / \mathrm{d}$ ratio of 1:1.5 and from then onwards decreases similar to the Eurocode prediction.

Figures 13 and 14 illustrate the variation of the across-wind base shear force against the building aspect ratio (width:length:height) for wind normal to long and short faces respectively. In general, more dispersion is observed here among the three approaches than in the along-wind response. Furthermore, in Figure 13, where wind is normal to the long face, the results of AIJ and AS/NZS converge together, whereas in Figure 14, where wind is normal to the short face, the two diverge further. It is observed that the dispersion between the two codes increases as the $b / d$ ratio decreases. The largest dispersion is observed in Figure 14 for the $198 \mathrm{~m}$ height category.

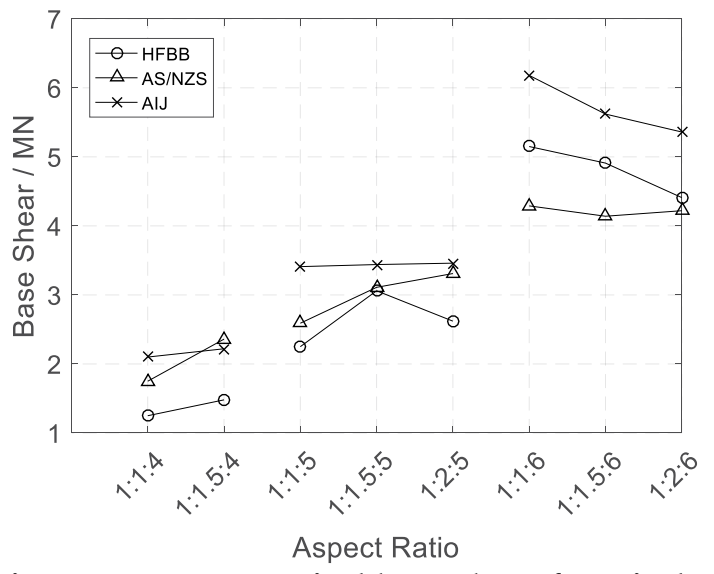

Figure 13 - Across-wind base shear for wind normal to long face

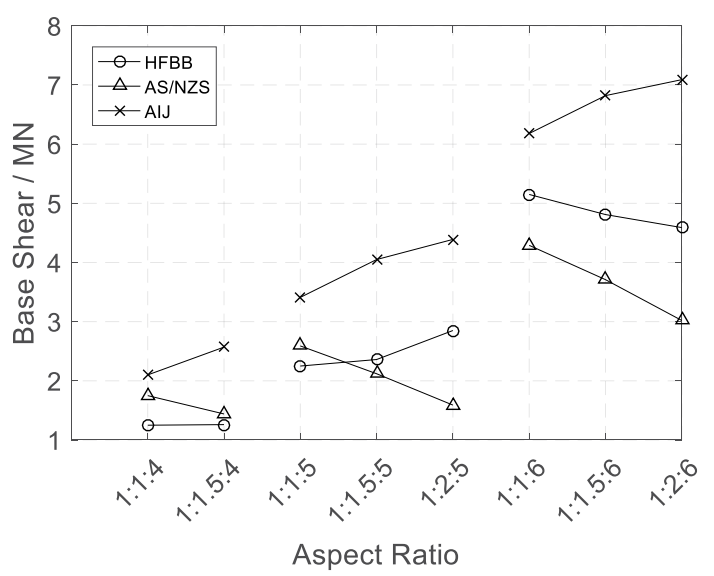

Figure 14 - Across-wind base shear for wind normal to short face

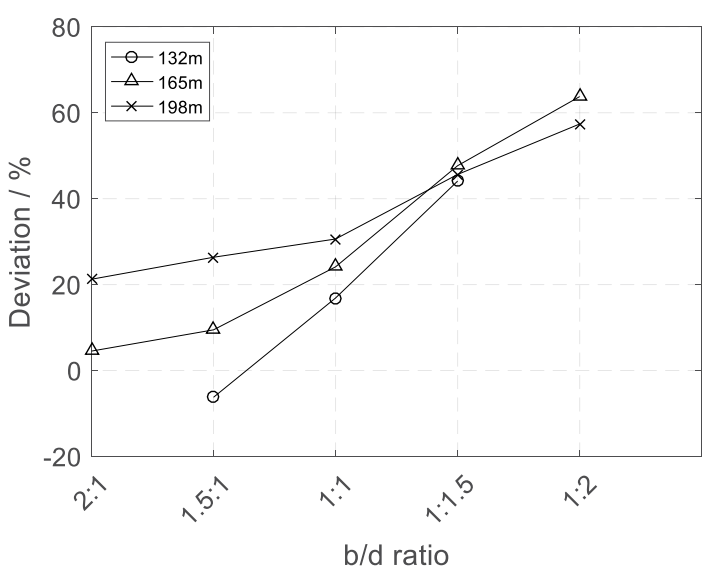

Figure 15 - Deviation between AIJ and AS/NZS for across-wind base shear 
Figure 15 further illustrates the discrepancy between AIJ and AS/NZS which accounts for the building $\mathrm{b} / \mathrm{d}$ ratio when predicting the across-wind base shear force. The percentage deviation of the AS/NZS prediction from the AIJ prediction is plotted against the building $\mathrm{b} / \mathrm{d}$ ratio. It can be observed that for all three height categories there is a similar variation in the deviation with the $b / d$ ratio. Therefore, irrespective of the height of the building it can be concluded that the deviation between AIJ and AS/NZS predictions for across-wind base shear force increases as the $\mathrm{b} / \mathrm{d}$ ratio decreases. As illustrated in Figure 61 the same phenomenon is evident in the across-wind acceleration as well.

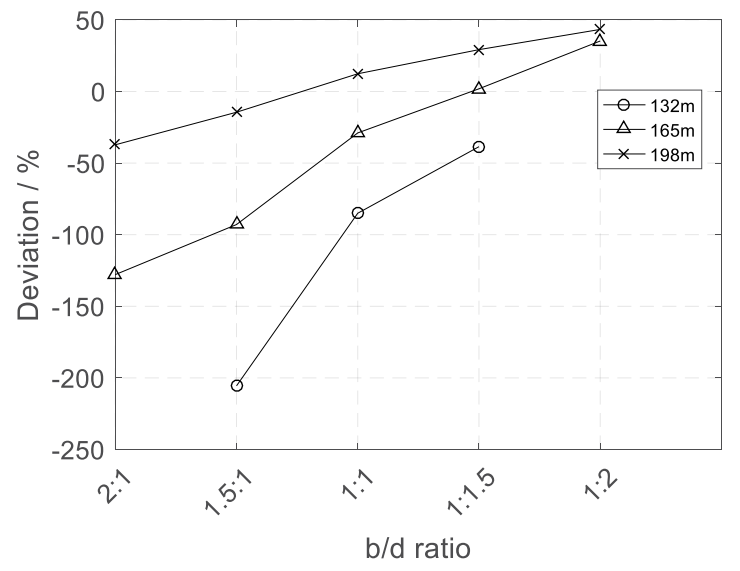

Figure 16 - Deviation between AIJ and AS/NZS for across-wind peak acceleration

Figure 17 illustrates the coefficient of variation of the along-wind and across-wind base shear force predictions of the different codes for wind normal to long and short faces. In general, it is observed that the coefficient of variation of the across-wind predictions is higher than that of the along-wind predictions. Furthermore, in both along-wind and across-wind predictions the coefficient of variation is higher when the wind is normal to the short face. Moreover, the coefficient of variation of the across-wind base shear decreases with the building height for all $\mathrm{b} / \mathrm{d}$ ratios which agrees with the observations made by [9]. Apparently, a distinctive deviation of the coefficient of variation can be observed in the across-wind base shear predictions for wind normal to the short face as the $b / d$ ratio decreases.

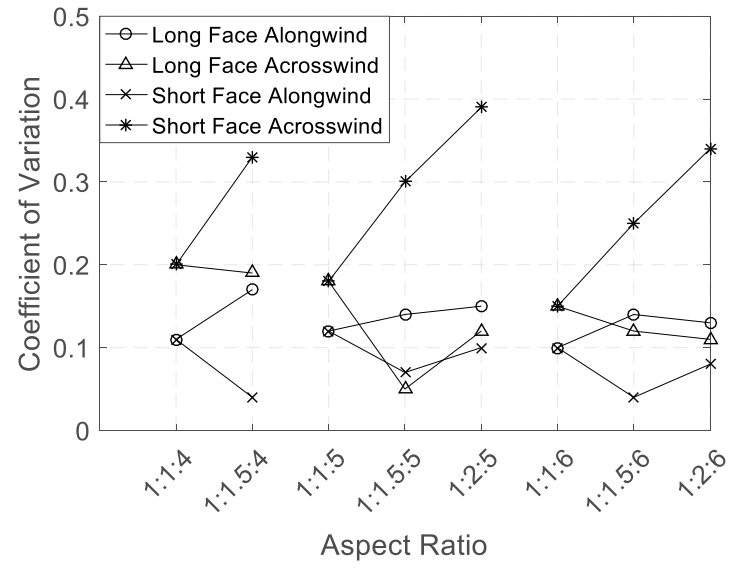

Figure 17 - Coefficient of variation of the base shear

\section{Conclusions}

The main objective of the study was to compare the predictions of wind-induced responses of tall buildings using CFD analysis and a set of wind codes: Eurocode, AS/NZS and AIJ, with reference to HFBB data analysis. It is observed that the maximum deviation between CFD and HFBB predictions for the base shear force and base bending moment are $5.7 \%$ and $8.1 \%$ respectively. Furthermore, the storey force distributions also correspond well with HFBB predictions. Therefore, it can be concluded that a steady state CFD analysis performed with a rigid body model using the two-Equation $\mathrm{k}-\epsilon$ turbulencemodel can predict with adequate accuracy global wind induced responses such as along-wind base shear, base bending moment and storey force distribution for tall buildings less than $200 \mathrm{~m}$ in height.

A fair correlation is observed among the codebased approaches in predicting along-wind responses with a coefficient of variation less than 0.2. However, some inconsistencies are observed among the wind codes when accounting for the effect of the $b / d$ ratio. AS/NZS and AIJ predictions remain constant as the $b / d$ ratio is changed (except for the square planar model in AIJ). HFBB prediction is nearly constant up to $\mathrm{a} b / \mathrm{d}$ ratio of $1: 1.5$ and decreases with the reduction of $b / d$ ratio, following the Eurocode prediction. Despite the different approaches in accounting for the effect of $b / d$ ratio on the building response, the low coefficient of variation indicates that the alongwind base shear predictions of the code-based approaches are reasonably accurate with reference to the HFBB value. 
However, significant deviations are observed in the across-wind predictions of the wind codes. This is particularly evident when wind is normal to the short face where the coefficient of variation is more than 0.3 . Furthermore, the contradictory ways of accounting for the $b / d$ ratio of buildings have contributed to a significant deviation between AIJ and AS/NZS predictions. This deviation is more pronounced when wind is normal to the short face of the building and further aggravates as the $b / d$ ratio decreases, reaching a coefficient of variation of 0.4 .

\section{References}

1. European Committee for Standardization (CEN). Eurocode 1: Actions on structures - Part 1-4: General actions - wind actions. EN 1991-14:2005/ AC:2010 (E). Europe: European Standard (Eurocode), European Committee for Standardization (CEN); 2010.

2. Joint Technical Committee. AS/NZS 1170.2:2011 Structural design actions - Part 2: Wind actions. Australian/New Zealand Standard (AS/NZS): Joint Technical Committee BD-006, Australia/New Zealand; 2011.

3. Zhou, Y., Kijewski, T., Kareem, A., Along-wind load effects on tall buildings: comparative study of major international codes and standards. journal of Structural Engineering. 2002 Jun;128(6):788-96.

4. Mendis, P., Ngo, T. D., Haritos, N., Hira, A., Samali, B., Cheung, J., Wind loading on tall buildings. Electronic Journal of Structural Engineering. 2007.

5. Kwok, K. C., Cross-wind response of tall buildings. Engineering Structures. 1982 Oct 1;4(4):256-62.

6. Davenport, A. G., Gust loading factors. Journal of the Structural Division. 1967 Jun;93(3):11-34.

7. Tamura, Y., Kareem, A., Solar, G., Kwok, K., Holmes, J. D., Melbourne, W. H., Aspects of the dynamic wind-induced response of structures and codification. Wind and Structures. 2005;8(4):251-68.

8. Kwon, D. K., Kareem, A.Comparative study of major international wind codes and standards for wind effects on tall buildings. Engineering Structures. 2013 Jun 1;51:2335.

9. Holmes J., Tamura, Y., Krishna, P., Comparison of wind loads calculated by fifteen different codes and standards, for low, medium and high-rise buildings. In 11th American conference on wind engineering, San Juan, Puerto Rico 2009 Jun 22.
10. Weerasuriya, A. U., Jayasinghe, M. T., Wind Loads on High-Rise Buildings by Using Five Major International Wind Codes and Standards. Engineer. 2014;47(03):13-25.

11. Architectural Institute of Japan (AIJ). RLB recommendations for loads on buildings. Tokyo (Japan): Structural Standards Committee, Architectural Institute of Japan; 2004.

12. Kwon, D. K., Kijewski-Correa T., Kareem, A. eAnalysis of high-rise buildings subjected to wind loads. Journal of Structural Engineering. 2008 Jul;134(7):1139-53.

13. American Society of Civil Engineers (ASCE).Minimum design loads for buildings and other structures. Reston (VA): ASCE; 2010

14. Murakami, S., Mochida, A., 3-D numerical simulation of airflow around a cubic model bymeans of the k-? model. Journal of Wind Engineering and Industrial Aerodynamics. 1988 Dec 1;31(2-3):283-303.

15. Murakami, S., Computational wind engineering. Journal of Wind Engineering andIndustrial Aerodynamics. 1990 Jan 1;36:517-38.

16. Hajra, B., Aboshosha, H., Bitsuamlak, G., Large eddy simulation of wind-induced pressure on a low rise building. InProceedings of the 25th Canadian Congress of Applied Mechanics (CANCAM), May 2015 May 31.

17. Tominaga, Y., Flow around a high-rise building using steady and unsteady RANS CFD: Effect of large-scale fluctuations on the velocity statistics. Journal of Wind Engineering and Industrial Aerodynamics. 2015 Jul 1;142:93-103.

18. Kijewski, T., Kareem, A., Dynamic wind effects: a comparative study of provisions in codes and standards with wind tunnel data. WIND STRUCTINT J. 1998 Mar;1(1):77109.

19. Solari, G., Gust buffeting. I: Peak wind velocity and equivalent pressure. Journal of Structural Engineering. 1993 Feb;119(2):365-82.

20. Kareem A. Acrosswind response of buildings. Journal of the Structural Division. 1982 Apr;108(4):869-87.

21. Griffis, L. G., Serviceability limit states under wind load. Engineering Journal-American Institute of Steel Construction Inc. 1993 Jan 1;30(1):1-6.

22. Zhou, Y., Kijewski, T., Kareem, A., Aerodynamic loads on tall buildings: interactive database. Journal of structural engineering. 2003 Mar;129(3):394-404. 
23. Elshaer, A., Aboshosha, H., Bitsuamlak, G., El Damatty, A., Dagnew, A., LES evaluation of windinduced responses for an isolated and a surrounded tall building. Engineering Structures. 2016 May 15;115:179-95.

24. Murakami, S., Overview of turbulence models applied in CWE-1997. Journal of Wind

Engineering and Industrial Aerodynamics. 1998 Apr 1;74:1-24.

25. Launder, B. E., Modeling flow-induced oscillations in turbulent flow around square cylinder. In ASME Fluid Eng. Conference 1993 (Vol. 20).

26. Tsuchiya, M., Murakami, S., Mochida, A., Kondo, K., Ishida, Y., Development of a new $k-\varepsilon$ model for flow and pressure fields around bluff body. Journal of Wind Engineering and Industrial Aerodynamics. 1997 Apr 1;67:169-82.

27. MengFQ, He BJ, Zhu, J., Zhao, D. X., Darko, A., Zhao, Z. Q., Sensitivity analysis of wind pressure coefficients on CAARC standard tall buildings in CFD simulations. Journal of Building Engineering. 2018 Jan 9. 